\title{
Effects of grinding environment on the flotation of Rosh Pinah complex $\mathrm{Pb} / \mathrm{Zn}$ ore
}

\author{
Y. Wei ${ }^{\mathrm{a}}$ and R.F. Sandenbergh ${ }^{\mathrm{a}}$ \\ ${ }^{\mathrm{a}}$ Department of Materials Science and Metallurgical Engineering, University of Pretoria, \\ Pretoria 0002, South Africa
}

\begin{abstract}
The Rosh Pinah orebody is a complex lead-zinc sulphide system with pyrite gangue and minor amounts of copper. Laboratory scale milling and flotation testing of ore samples taken from this operation was performed. Different grinding media and conditions were used, including ceramic, stainless steel and steel. Flotation tests used a sequential recovery protocol for selective flotation of first the lead and thereafter the zinc. The presence of species of oxidation products on the ore after milling was probed using ethylene diamine tetra-acetic acid (EDTA) leaching. The test data show that, for comparable grinds and reagent dosages, the choice of grinding media has a marked effect on the paymetals recoveries and the selectivity. The ceramic mill produced the highest recoveries but the poorest selectivity. The steel mill produced the converse result. It is proposed that this is because the ceramic mill produces an oxidizing environment, allowing sphalerite activation by copper ions, whilst the steel mill produces a reducing environment, preventing this activation.
\end{abstract}

\section{Article Outline}

1. Introduction

2. Experimental 


\subsection{Ore}

2.2. Chemicals and water

2.3. Grinding and flotation

2.4. EDTA leaching, chemical phase analysis and solution analysis

3. Results

3.1. Flotation performance as a function of milling environment

3.2. Flotation kinetics

3.3. Size-by-size recovery distributions for different milling methods

3.4. Pulp chemistry after milling

4. Discussion

5. Conclusions

Acknowledgements

References

\section{Introduction}

Comminution of complex ores is typically necessary to liberate the sought after minerals to allow for their selective recovery during recovery processes such as flotation. The comminution process inevitably involves contact of the ore with the surface of comminution device and in the case of ball or rod milling also with the grinding medium. This not only causes wear, but also contamination of the ore with wear debris as well as with precipitated species on the ore surfaces. If milling is done in an aqueous medium, corrosion of the ore and the medium can lead to complex interactions, such as galvanic effects, changes in the Eh of solution and the dissolution and precipitation of species on the ore surfaces. Galvanic interactions between the steel grinding media and sulphide ores will typically increase steel consumption and reduce the corrosion of more noble sulphides, with commensurate higher oxygen consumption, and the possible precipitation of iron species on the ore particles (Wang and Xie, 1990, Natarajan, 1992 and Natarajan, 1996). Steel media wear during grinding may be reduced in a number of ways, such as using rubber liners, corrosion resistant media and corrosion inhibitors (Natarajan, 1992, Natarajan, 1996, Pradip, 1992 and Ayyala et al., 1993). 
As expected, the interactions between the ore and milling environment affect sulphide flotation both in recovery and selectivity (Forssberg et al., 1988, Forssberg et al., 1993, Greet et al., 2005, Kocabag and Smith, 1982 and Wang and Xie, 1990). Rey and Formanek (1960) first demonstrated the effects of milling on the selective flotation of $\mathrm{Pb} / \mathrm{Zn}$ ores. Using synthetic lead-zinc ores (mixing of galena, sphalerite, cerussite and anglesite) they found that sphalerite showed natural floatability, as well as some extent of activation by lead ions, which reduced its separation from galena when ground in a porcelain mill. Grinding this ore in an iron mill reduced the natural floatability of sphalerite significantly. Many industrial circuits also showed significant effects of milling on sulphide flotation (Kocabag and Smith, 1982, Forssberg et al., 1988 and Forssberg et al., 1993). The depression of sulphide flotation after milling in a steel mill, which typically results in a less oxidising environment, could be due to the unselective coating of the sulphides by iron oxidation products, or failure to oxidise the collector to its hydrophobic species. The prevention of corrosion in the milling process may thus reduce the cost of grinding and improve flotation recovery, but may, unfortunately, reduce the selectivity of the process. The application of high chromium grinding media was tested and proved to be a viable measure to improve lead flotation recovery by Greet et al., 2004 and Greet et al., 2005.

In this work, ceramic, stainless and steel mills were used to compare the effect of the milling environment on the flotation of a complex sulphide ore.

\section{Experimental}

\subsection{Ore}

A complex $\mathrm{Pb}-\mathrm{Zn}$ ore from Rosh Pinah, Namibia was used for all the experiments. The ore sample taken from the plant mill feed was crushed to below $3.35 \mathrm{~mm}$ at the mine and riffled into $20 \mathrm{~kg}$ lots using a spinning riffler. It was further crushed to $-2 \mathrm{~mm}$ at the lab using a gyratory crusher, homogenized and rotatory riffled to $1 \mathrm{~kg}$ lots and stored in plastic bags until final milling just prior to the experiments. The chemical composition of the sample is shown in Table 1. 
Table 1.

The chemical composition of the ore (mass \%)

\begin{tabular}{|l|l|l|l|l|l|l|l|l|l|}
\hline $\mathbf{P b}$ & $\mathrm{Zn}$ & $\mathbf{C u}$ & $\mathrm{Fe}$ & $\mathbf{S}$ & $\mathbf{C a O}$ & $\mathrm{MgO}$ & $\mathbf{B a O}$ & $\mathbf{A l}_{2} \mathbf{O}_{3}$ & $\mathrm{SiO}_{2}$ \\
\hline 2.69 & 11.91 & 0.17 & 6.19 & 7.48 & 22.98 & 10.52 & 5.22 & 3.17 & 25.15 \\
\hline
\end{tabular}

\subsection{Chemicals and water}

The collector used in the experiments was sodium normal propyl xanthate (SNPX) provided by Senmin, South Africa and was used as supplied. This collector is currently used at Rosh Pinah. Industrial frother (Dow 250) was used for all the flotation experiments. High purity argon gas (>99.999\%) was used as protective gas for the EDTA leach tests and ammonium acetate selective leaching. EDTA and all the other reagents used in the experiments were of analytical grade quality. Water used in the experiments was Pretoria tap water.

\subsection{Grinding and flotation}

Three kinds of mills were used in the experiments namely stainless steel and steel rod mills of the identical size and a ceramic ball mill. One kilogram of ore was ground wet in the different mills at a mass concentration of $66.7 \%$. The fineness of ground product, represented as percent mass passing $75 \mu \mathrm{m}$, was controlled by varying the time of milling. Conditioning and flotation were conducted in a 2 L flotation cell (Denver 12) at an unadjusted $\mathrm{pH}$ of 7.8-8.2. The pulp was stirred for $3 \mathrm{~min}$ before adding SNPX $(50 \mathrm{~g} / \mathrm{t})$, followed by conditioning for $5 \mathrm{~min}$, and the addition of frother (Dow frother $250,12 \mathrm{~g} / \mathrm{t}$ ), followed by 3 min conditioning. Flotation was conducted at a concentration of $32 \%$ solids by mass. The flotation machine was operated at an impeller speed of $1150 \mathrm{rpm}$. Froth was continuously removed from the cell by an automatic scraper operating at a speed of 26 revolutions per minute (rpm). The sides of the cell were washed with tap water during the flotation, and the pulp was kept at a constant level by adding tap water. The total flotation time was $16 \mathrm{~min}$. Pulp potential (Eh) and dissolved oxygen (DO) levels were recorded continuously from the beginning of conditioning to the end of flotation using an Orion composite platinum electrode and a DO probe. 
Flotation products were analyzed using X-ray fluorescence spectrometry (XRF) and conventional wet screening. A modified Kelsall first order model (Kelsall, 1961 and Lynch et al., 1981), with fast and slow-floating distribution, as shown in Eq. (1) was used to assess the flotation results. The flotation parameters were calculated by fitting the experimental data through Sigmaplot (version 7.0) according to the regression Eq. (1):

$$
R_{t}=R_{\max }\left\{1-\left((1-\theta) \mathrm{e}_{\mathrm{f}}^{-k t}+\theta \mathrm{e}_{\mathrm{s}}^{-k t}\right)\right\}
$$

where $R_{t}$ is the cumulative floatation recovery of mineral at time $t, R_{\max }$ is the ultimate flotation recovery, $k_{\mathrm{f}}, k_{\mathrm{s}}$ are the fast-floating and slow-floating rate constants, respectively, and $\theta$ is the slow floating fraction.

\subsection{EDTA leaching, chemical phase analysis and solution analysis}

EDTA leaching was used to quantify the precipitates on the ore using the procedure recommend by Greet and Smart (2002), with a few minor modifications. A $20 \mathrm{~mL}$ of sample of pulp was taken after the 3 min stirring and added to $250.00 \mathrm{~g}$ of previously argon purged (for at least $30 \mathrm{~min}$ ) $0.1 \mathrm{M}$ EDTA solution of $\mathrm{pH} 7.5$ (adjusted with potassium hydroxide). The slurry was stirred vigorously under argon for 5 min before filtering through a $0.22 \mu \mathrm{m}$ Millipore filter. A $50 \mathrm{~mL}$ sample of the filtrate was analyzed using ICP. Copper was analysed by ICP plus MS.

The real concentration of the EDTA leachable metal ions in the pulp can be calculated approximately according to the following formula:

$$
\begin{gathered}
C_{1}=\frac{C_{9} \times 0.266}{0.02} \times 1 \quad(\mathrm{mg} L \mathrm{Lul} p) \\
C_{2}=C_{1} \times 2.2 \times 10^{-3} \quad(\mathrm{~g} / \mathrm{t})
\end{gathered}
$$

where $C_{0}$ is the measured concentration of the EDTA leachate, $C_{1}$ is the converted metal concentration in pulp and $C_{2}$ is the corresponding equivalent dosage of that metal in pulp. The solution volumes of total EDTA leaching solution, pulp solution sampled and total pulp volume, are $0.266,0.02$ and $2.2 \mathrm{~L}$, respectively. 
The analysis of the oxidised lead was done using the procedure recommended by Young (1974) as guideline. Two grams of $-0.074 \mu \mathrm{m}$ sample was added to $200 \mathrm{~mL}$ of argon purged 60\% ammonium acetate solution and stirred under argon for $1.5 \mathrm{~h}$. A $50 \mathrm{~mL}$ sample of the filtrate was analyzed after filtration and dilution, using ICP.

\section{Results}

\subsection{Flotation performance as a function of milling environment}

The flotation recovery of various minerals from Rosh Pinah ore, as represented by their indicator elements, versus grinding fineness, is shown in Fig. 1, Fig. 2 and Fig. 3 for the different milling environments. These experiments were conducted without any cyanide addition.

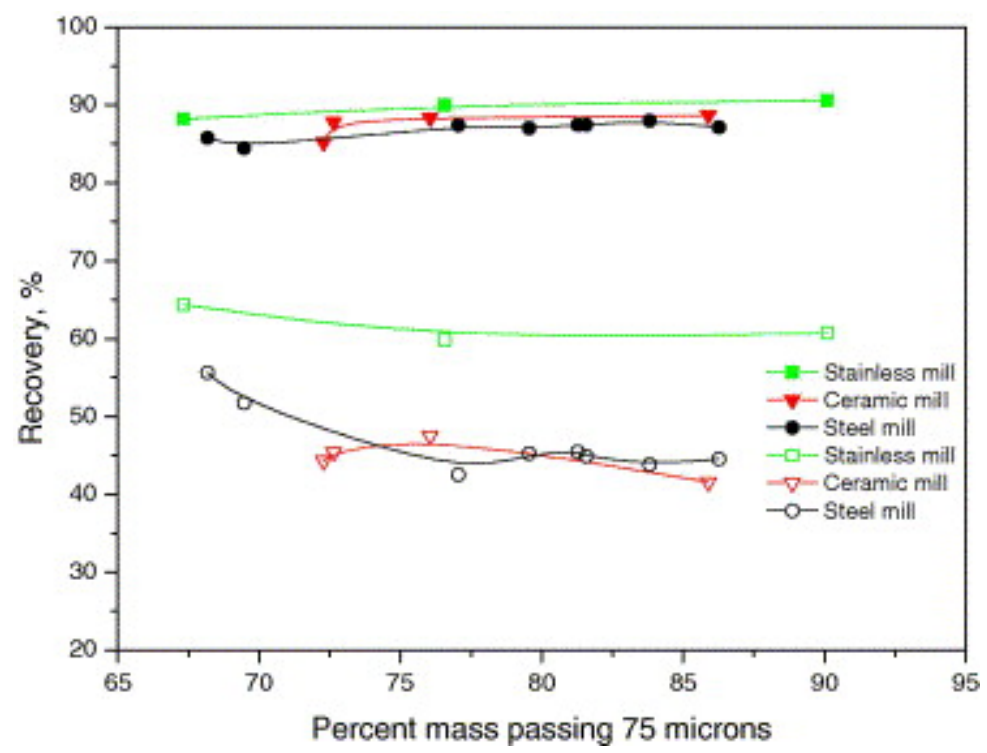

Fig. 1. Flotation recovery of lead (filled symbol) and zinc (hollow symbol) containing minerals from Rosh Pinah ore as a function of particle size after milling in different environments. 


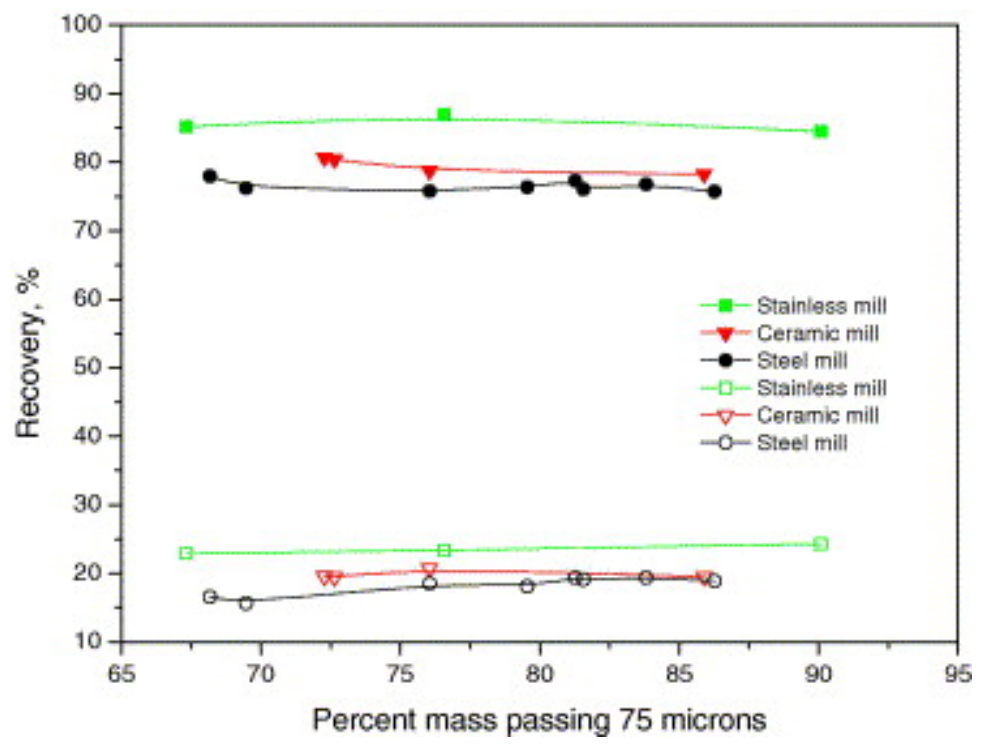

Fig. 2. Flotation recovery of iron (filled symbol) and silicon (hollow symbol) containing minerals from Rosh Pinah ore as a function of particle size after milling with different mills.

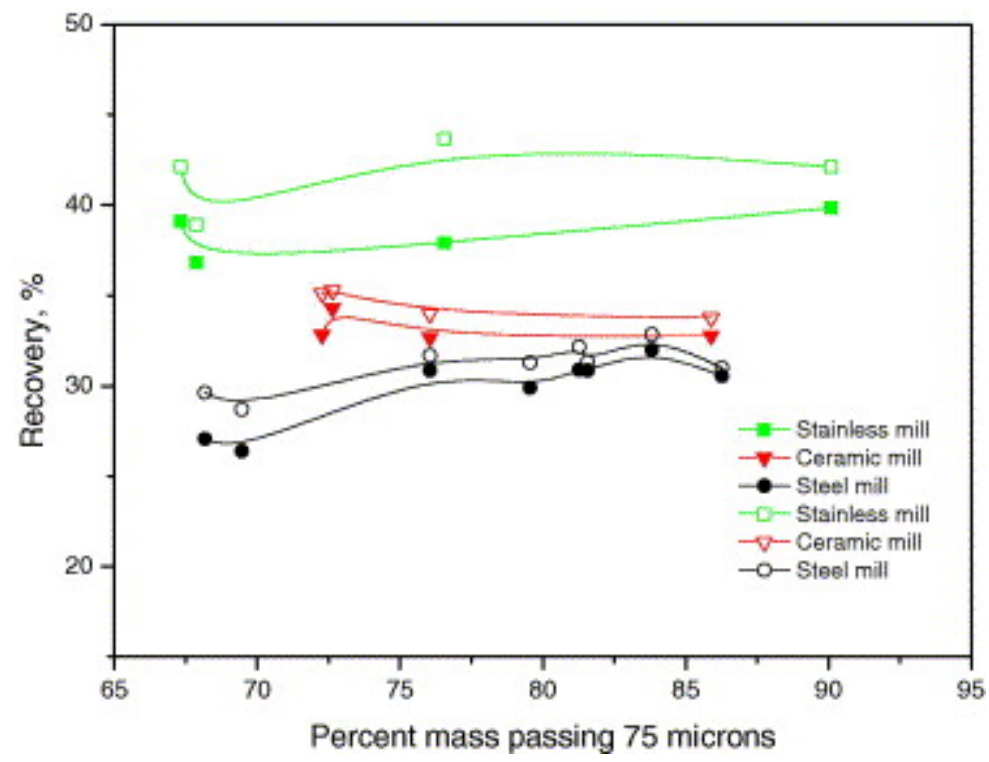

Fig. 3. Flotation recovery of calcium (filled symbol) and magnesium (hollow symbol) containing minerals from Rosh Pinah ore as a function of particle size after milling in different environments.

Milling in stainless steel resulted in the highest recovery of lead over the whole size range, but unfortunately also gave the highest recovery of zinc, iron, and other nonsulphide gangue minerals. Milling in the ceramic mill gave similar results, but with lower 
zinc recovery, while milling in the steel mill resulted in somewhat lower lead recovery, and also with lower zinc recovery. There was only a slight decrease in zinc recovery as the grinding fineness increased while the recovery of lead was not affected by the grinding fineness, indicating that the lead and zinc minerals are liberated from each other at grinds of more than $75 \%-75 \mu \mathrm{m}$. Rougher flotation at a coarser grind followed by regrinding to liberate the lead and zinc from each other has been suggested by Seke and Pistorius (2005) as a method to optimise both the grade and recovery of the lead and zinc concentrates recovered from this ore.

Pyrite (iron) recovery for all the three milling environments was very high and showed little change as the grinding fineness increased, probably resulting from the good floatabilities of pyrite with SNPX. The flotation of the non-sulphide gangue minerals were also significantly affected by the different milling environments with the best recovery with the stainless steel, and the poorest with the carbon steel. It can be concluded that milling in a stainless mill increased the recovery for all the minerals, while milling in a steel mill decreased the flotation of all the minerals, although to different extents, while milling in a ceramic mill gave intermediate results. However, the ceramic mill was a ball mill, whereas the stainless and steel mills were rod mills, and different size distributions might have contributed to the difference in flotation behaviour.

\subsection{Flotation kinetics}

The kinetics of flotation after comminution in the different milling environments was characterized using a grind fineness of about $76 \%-75 \mu \mathrm{m}$ where good liberation between the lead and zinc minerals should be achieved. The particle size distribution after milling in the three types of mill is given in Table 2.

Table 2.

The particle size distribution of Rosh Pinah ore after milling in the three kinds of mills to the same fineness $(\%)$ 


\begin{tabular}{|l|l|l|l|l|l|l|}
\hline Particle range $(\boldsymbol{\mu m})$ & \multicolumn{2}{|l|}{ Steel mill } & \multicolumn{2}{l|}{ Stainless mill } & \multicolumn{2}{l|}{ Ceramic mill } \\
\hline & Con. & Tail. & Con. & Tail. & Con. & Tail. \\
\hline+106 & 3.03 & 11.44 & 4.17 & 5.81 & 4.25 & 7.87 \\
\hline$-106+75$ & 2.02 & 6.54 & 6.33 & 7.12 & 4.26 & 7.56 \\
\hline$-75+53$ & 4.27 & 7.75 & 7.70 & 8.39 & 5.32 & 8.41 \\
\hline$-53+45$ & 3.25 & 4.64 & 4.55 & 4.39 & 2.82 & 4.80 \\
\hline$-45+38$ & 2.85 & 4.62 & 3.02 & 3.92 & 2.67 & 4.54 \\
\hline-38 & 19.23 & 30.36 & 19.84 & 24.76 & 18.45 & 29.05 \\
\hline Total & & & & & & \\
\hline Con & 34.65 & 65.35 & 45.61 & 54.39 & 37.77 & 62.23 \\
\hline
\end{tabular}

Con. $=$ concentrate, Tail. $=$ Tailing.

Fig. 4, Fig. 5 and Fig. 6 show the flotation recoveries of various elements after grinding Rosh Pinah ore in the three milling environments, while the corresponding modified Kelsall model parameters for the flotation of the elements are shown in Table 3. The Kelsall model fitted the experimental data very well, with correlation coefficients of greater than 0.99 achieved for most cases. Fig. 7 illustrates the relation between lead grade and recovery for the three mill types. Fig. 8 and Fig. 9 illustrate the flotation selectivity between $\mathrm{Pb}-\mathrm{Zn}$ and $\mathrm{Pb}-\mathrm{Fe}$, respectively. 


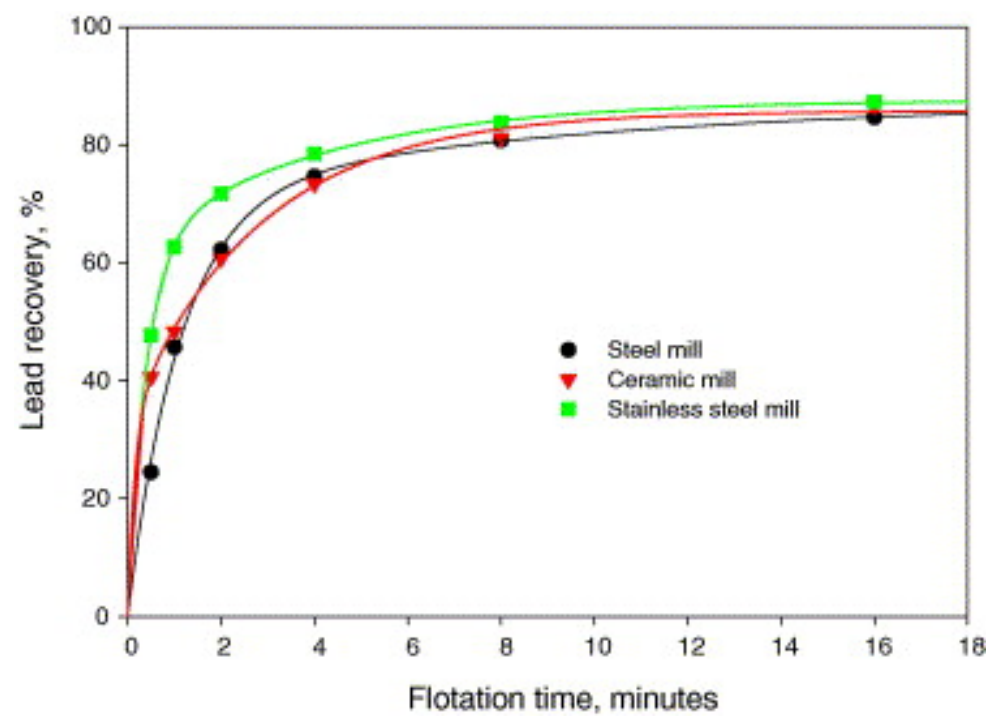

Fig. 4. Flotation recovery of lead minerals vs. flotation time of Rosh Pinah ore for the indicated milling methods. The lines illustrate the Kelsall regression fits to the experimental data points.

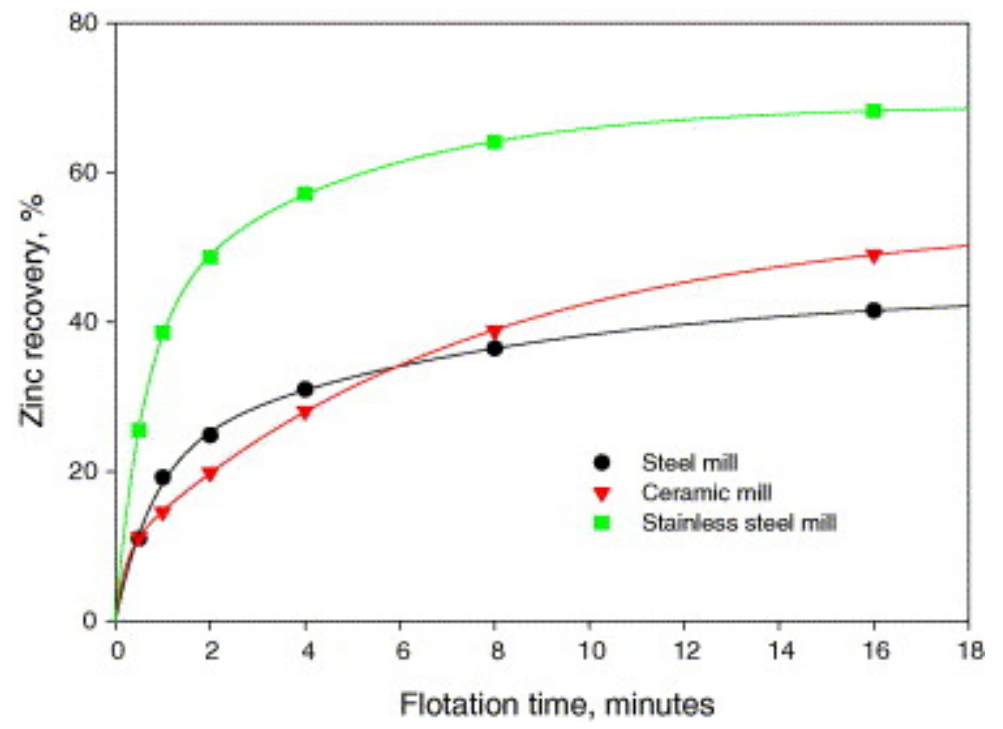

Fig. 5. Flotation recovery of zinc minerals vs. flotation time of Rosh Pinah ore for the milling methods indicated. The lines illustrate the Kelsall regression fits to the experimental data points. 


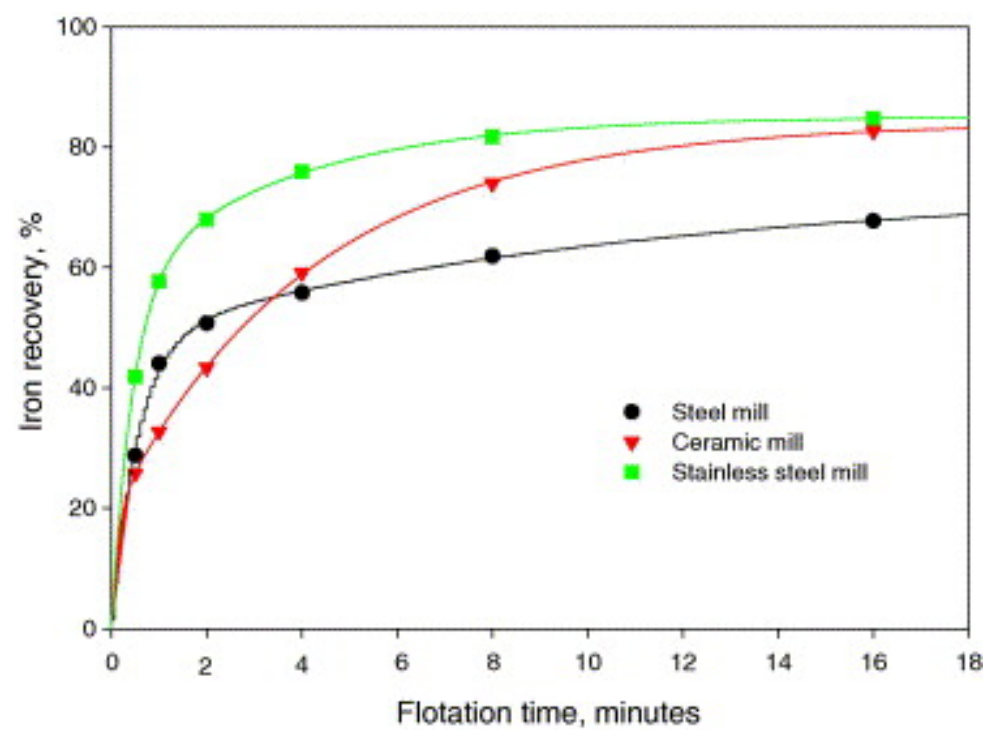

Fig. 6. Flotation recovery of iron minerals vs. flotation time for the milling methods indicated. The lines illustrate the Kelsall regression fits to the experimental data points. Table 3.

Modified Kelsall model values obtained for the flotation of various minerals present in Rosh Pinah ore after milling in the environments indicated

\begin{tabular}{|l|l|l|l|l|l|l|}
\hline & $\boldsymbol{R}_{\max }(\mathbf{\%})$ & $\theta_{\mathrm{s}}$ & $\boldsymbol{\theta}_{\mathrm{f}}$ & $\boldsymbol{k}_{\mathbf{s}}\left(\mathbf{m i n}^{-1}\right)$ & $\boldsymbol{k}_{\mathbf{f}}\left(\mathbf{m i n}^{-1}\right)$ \\
\hline Lead minerals & \multicolumn{5}{|l}{} \\
\hline Steel mill & 87.79 & 0.19 & 0.81 & 0.10 & 0.89 \\
\hline Ceramic mill & 85.73 & 0.61 & 0.39 & 0.35 & 6.51 \\
\hline Stainless mill & 87.56 & 0.29 & 0.71 & 0.25 & 2.53 \\
\hline & & & & & \\
\hline Zinc minerals & & & & & \\
\hline Steel mill & 44.13 & 0.51 & 0.49 & 0.13 & 1.27 \\
\hline Ceramic mill & 54.03 & 0.83 & 0.17 & 0.14 & 4.81 \\
\hline Stainless mill & 69.01 & 0.43 & 0.57 & 0.22 & 1.69 \\
\hline
\end{tabular}




\begin{tabular}{|l|l|l|l|l|l|}
\hline & $R_{\max }(\%)$ & $\theta_{\mathrm{s}}$ & $\theta_{\mathrm{f}}$ & $k_{\mathrm{s}}\left(\mathrm{min}^{-1}\right)$ & $k_{\mathrm{f}}\left(\min ^{-1}\right)$ \\
\hline & & & & & \\
\hline
\end{tabular}

\section{Iron minerals}

\begin{tabular}{|l|l|l|l|l|l|}
\hline Steel mill & 73.55 & 0.34 & 0.66 & 0.09 & 1.80 \\
\hline Ceramic mill & 83.99 & 0.77 & 0.23 & 0.24 & 7.30 \\
\hline Stainless mill & 85.04 & 0.33 & 0.67 & 0.28 & 2.24 \\
\hline
\end{tabular}

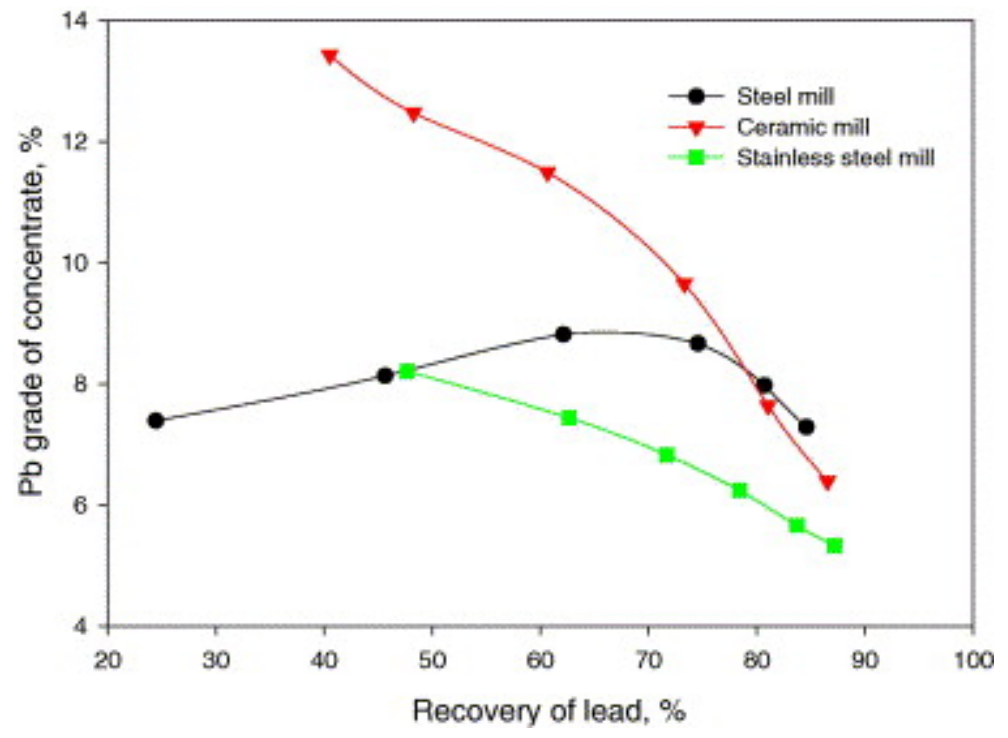

Fig. 7. The lead grade vs. lead recovery curve for the three mills used.

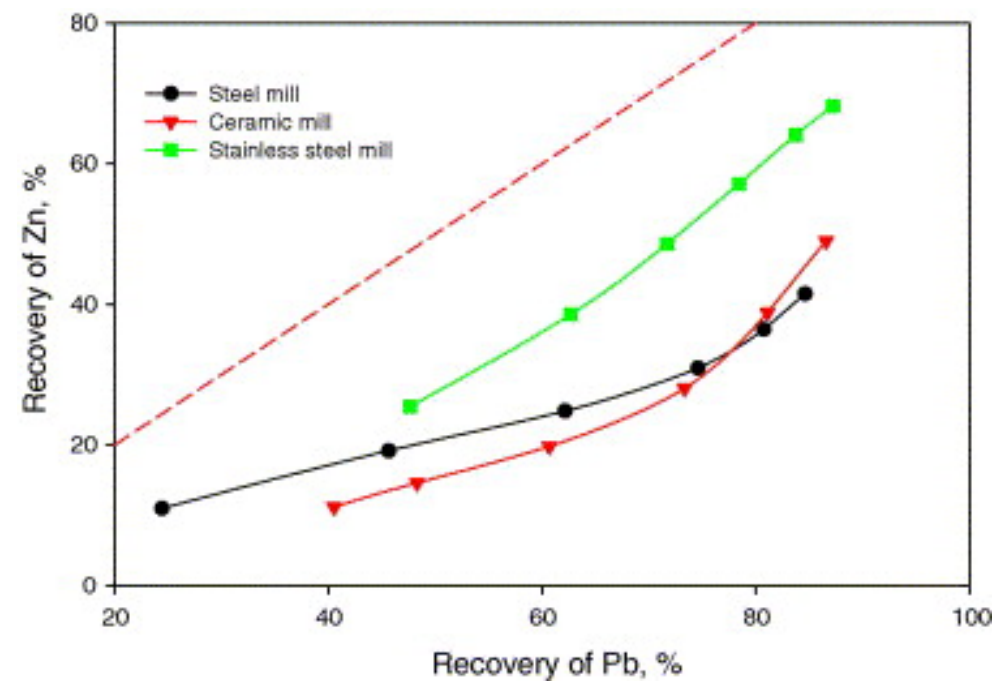


Fig. 8. Flotation selectivity between lead and zinc for the three mill types indicated. The dotted line represents the condition where no separation exists between lead and zinc.

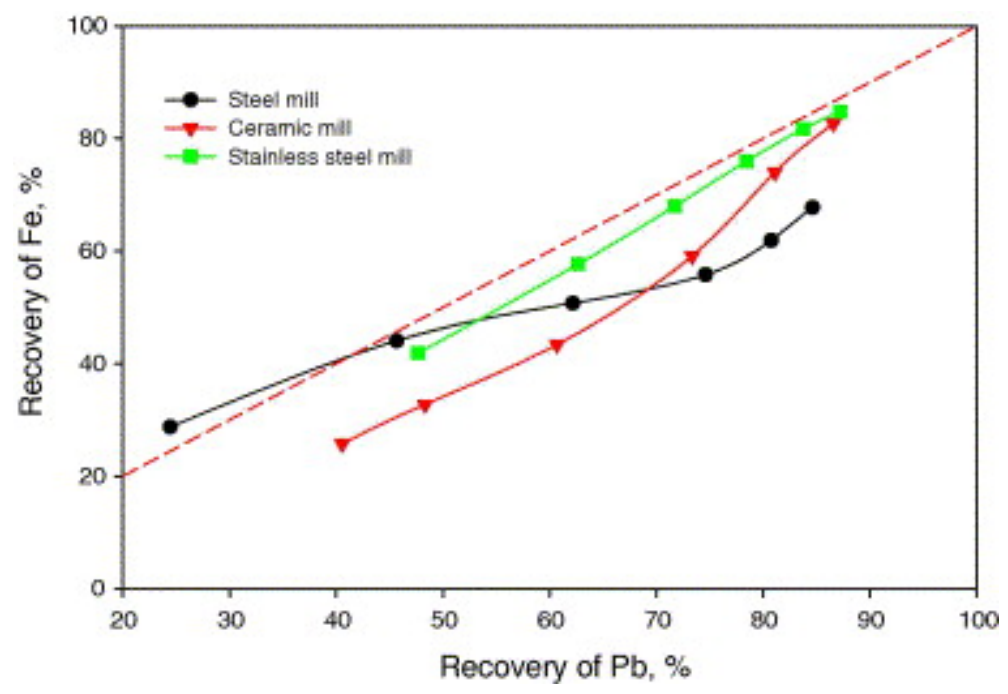

Fig. 9. Flotation selectivity between lead and iron for the three mill types indicated. The dotted line represents the condition where no separation exists between $\mathrm{Pb}$ and $\mathrm{Fe}$. These flotation results indicate that lead flotation recovery was insensitive to the milling environment, with only a small difference in the ultimate flotation recovery predicted for the three milling environments. The flotation was fast and highly selective in the beginning stages of flotation when milling in a ceramic mill, but the selectivity decreased to that obtained with the other milling environments as flotation progressed, as shown in Fig. 7. The fast flotation rate constant for galena in the steel mill was quite low compared with the rate constants of other minerals, which is probably the result of the precipitation of iron corrosion products on the surface of the galena.

For the sphalerite minerals much higher initial flotation rates was obtained in the ceramic and stainless steel environments, indicating that sphalerite was either activated during milling, or not depressed by the precipitation of ferrous corrosion products, as the case would be in the steel mill. The behaviour of the pyrite is interesting in the sense that its flotation kinetics after steel milling was initially fast, but with a lower final recovery indicating the selective flotation inhibition of the iron sulfides by iron oxidation products. 


\subsection{Size-by-size recovery distributions for different milling methods}

Analysis of the influence of size on the flotation behaviour of particles is a useful diagnostic technique extensively used by researchers, both in plant surveys and laboratory batch flotation tests (Kelsall, 1961 and Trahar, 1981). Fig. 10 and Fig. 11 give the size-by-size recovery distribution for lead and zinc, respectively. For all the three milling methods evaluated, the lead recovery distribution profiles were similar to the typical size recovery distributions reported in the literature (Trahar, 1981, Lynch et al., 1981 and Vianna et al., 2003). However, the optimal floatable size range of the steel milled ore was quite narrow compared to those after milled in the stainless or ceramic mills. Milling in a steel mill decreased the floatability of the coarser particles, but did not affect the finer particles. It should be noted that although the overall recoveries of lead showed no significant difference in these experiments, as shown in Fig. 1, the size-bysize recovery of the three milling methods revealed quite different flotation behaviours. Zinc flotation recovery was less dependent on size, but was strongly influenced by the comminution environment as already shown in Fig. 1 and Fig. 8.

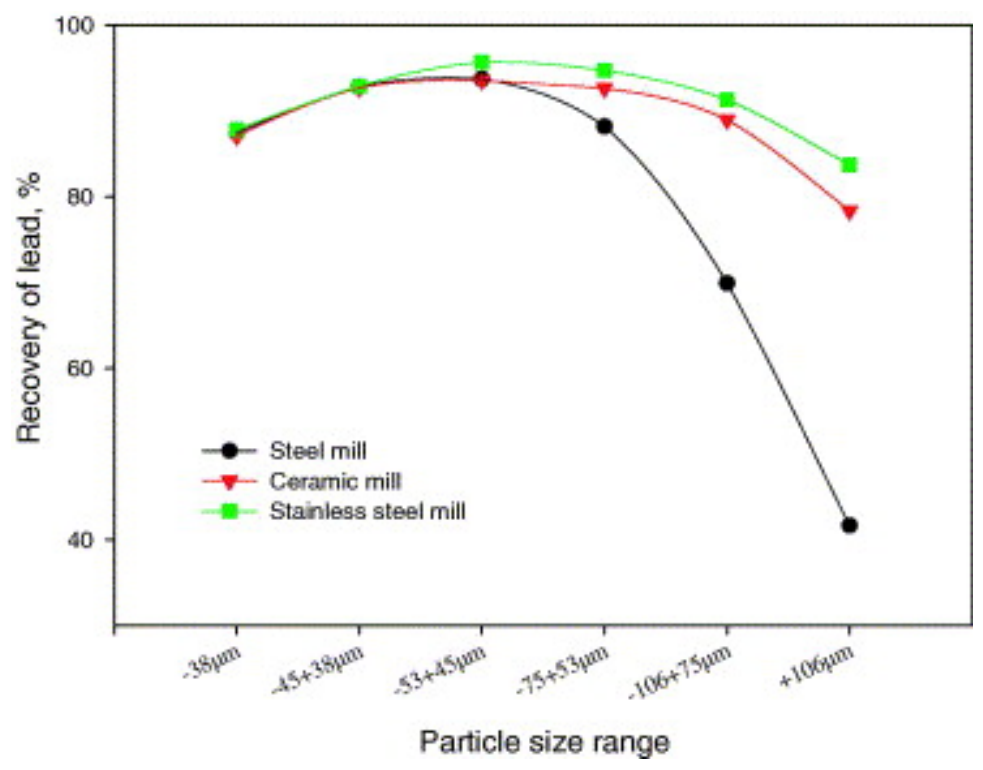

Fig. 10. Size-by-size flotation recovery of lead from Rosh Pinah ore after $16 \mathrm{~min}$ flotation. 


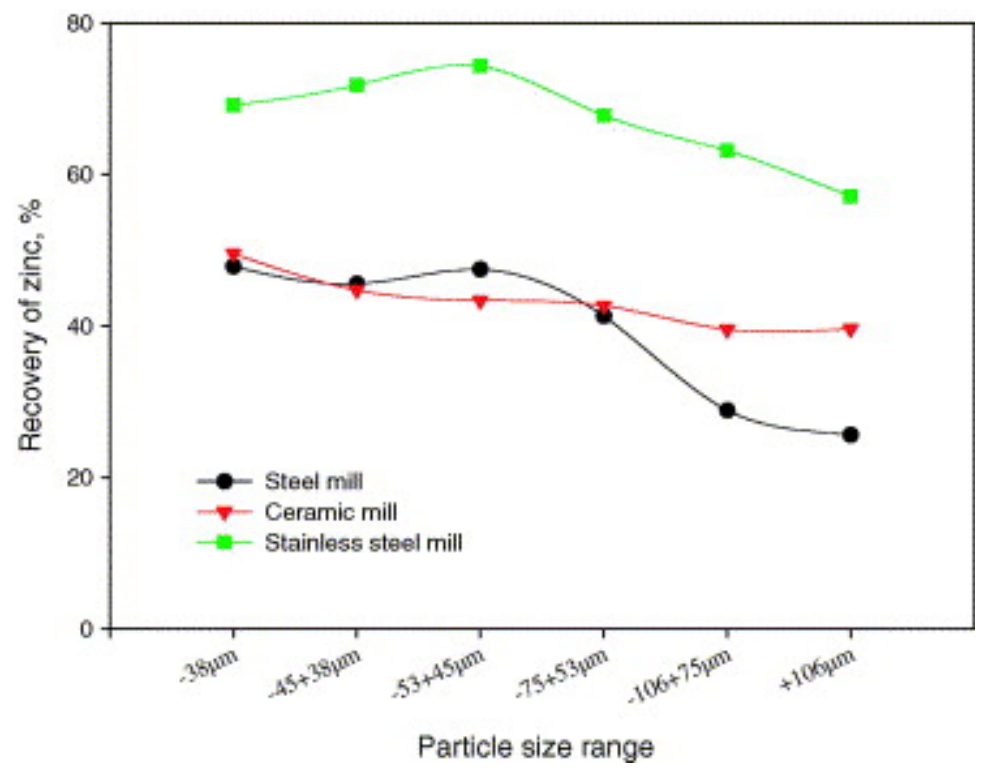

Fig. 11. Size-by-size flotation recovery of zinc from Rosh Pinah ore after $16 \mathrm{~min}$ flotation.

\subsection{Pulp chemistry after milling}

The results so far indicated that the different comminution environments may have a significant influence on the flotation behaviour of the Rosh Pinah ore, and that this may be due to species precipitating on the mineral surfaces. Some indication of the dissolution of the species from the minerals may be obtained from solution analyses, but this is typically not a good indicator as many metal cations precipitate out of solution at the conditions typically used for flotation. Some idea of the species precipitated on the mineral surfaces may be obtained by leaching with a metal complexant, such as EDTA, provided that significant further dissolution of the minerals themselves do not take place during the test. Previous experiments (Forssberg et al., 1988 and Wei and Sandenbergh, 2005) indeed showed that analysing the filtrate solution only is not a suitable technique to determine the dissolution of the ore and milling medium because of the precipitation of most heavy metal ions in the alkaline conditions typically for flotation processes. Table 4 gives the composition of the leachate of EDTA leaching of pulps prepared in different milling environments. Table 5 gives the selective leaching analysis results of the ore prior to the milling. The dissolved oxygen (DO) and Eh variations occurring during flotation are shown in Fig. 12. Table 6 gives the comparison results between solution and pulp for 
steel mill. The metal concentration value in solid is obtained by the deduction of solution metal concentration (Wei and Sandenbergh, 2005) from the EDTA extractable metal concentration.

Table 4.

Chemical composition of the EDTA leachate from Rosh Pinah pulp prepared in the milling environments indicated $(\mathrm{mg} / \mathrm{L})$

\begin{tabular}{|l|l|l|l|l|}
\hline Element & Stainless & Steel & Ceramic & Detection limit \\
\hline $\mathrm{Ba}$ & 100 & 110 & 66 & 0.2 \\
\hline $\mathrm{Ca}$ & 120 & 130 & 80 & 0.5 \\
\hline $\mathrm{Cu}$ & $94 \mathrm{ppb}$ & $9.8 \mathrm{ppb}$ & $150 \mathrm{ppb}$ & $5 \mathrm{ppb}$ \\
\hline $\mathrm{Fe}$ & 4.6 & 140 & 3.2 & 0.2 \\
\hline $\mathrm{K}$ & 3600 & 3700 & 3800 & 0.2 \\
\hline $\mathrm{Mg}$ & 21 & 27 & 14 & 0.2 \\
\hline $\mathrm{Mn}$ & 11 & 15 & 7.5 & 0.1 \\
\hline $\mathrm{Na}$ & 4500 & 4700 & 4700 & 0.5 \\
\hline $\mathrm{Pb}$ & 150 & 110 & 130 & 3 \\
\hline $\mathrm{S}$ & 26 & 28 & 26 & 6 \\
\hline $\mathrm{Si}$ & 3.2 & 4.7 & 3.2 & 3 \\
\hline $\mathrm{Sr}$ & 3.1 & 3.4 & 2.0 & 0.2 \\
\hline $\mathrm{Zn}$ & 21 & 23 & 22 & 1.7 \\
\hline
\end{tabular}


Table 5.

The contents of soluble metal from selective leaching of Rosh Pinah ore (\%)

\begin{tabular}{|l|l|l|l|l|}
\hline Leaching methods & Pb & Cu & Zn & Note \\
\hline Ammonium acetate & 11.61 & 1.90 & 1.35 & Oxidized lead \\
\hline EDTA & 10.71 & 0.86 & 1.35 & Oxidized metals \\
\hline $\mathrm{HCl}+\mathrm{HNO}_{3}$ & 100 & 100 & 100 & All sulphides \\
\hline
\end{tabular}

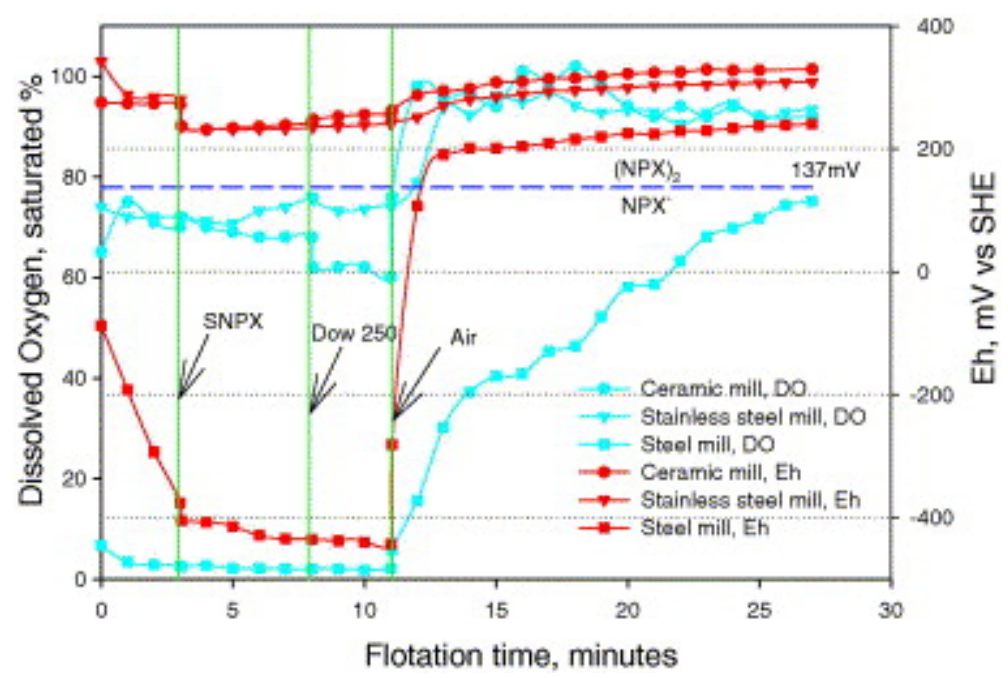

Fig. 12. Dissolved oxygen (DO) and Eh changes during flotation after milling in the mills indicated.

Table 6.

The comparison of major metal ion concentrations in different states $(\mathrm{mg} / \mathrm{L})$

\begin{tabular}{|l|l|l|l|}
\hline Element & In solution & EDTA extractable & In solid \\
\hline $\mathrm{Ba}$ & 0.1 & 1463.00 & 1462.9 \\
\hline $\mathrm{Ca}$ & 110 & 1729.00 & 1619 \\
\hline $\mathrm{Cu}$ & $<0.03$ & 0.13 & 0.1 \\
\hline $\mathrm{Fe}$ & 0.54 & 1862.00 & 1861.46 \\
\hline
\end{tabular}




\begin{tabular}{|l|l|l|l|}
\hline Element & In solution & EDTA extractable & In solid \\
\hline $\mathrm{Mg}$ & 35 & 359.10 & 324.1 \\
\hline $\mathrm{Mn}$ & 0.4 & 199.50 & 199.1 \\
\hline $\mathrm{Pb}$ & $<0.31$ & 1463.00 & 1462.69 \\
\hline $\mathrm{S}$ & - & 372.40 & 327.40 \\
\hline $\mathrm{Si}$ & 2.1 & 62.51 & 60.41 \\
\hline $\mathrm{Sr}$ & 0.82 & 45.22 & 44.4 \\
\hline $\mathrm{Zn}$ & $<0.17$ & 305.90 & 305.73 \\
\hline $\mathrm{Th}$ & & & \\
\hline
\end{tabular}

The results in Table 4 and Table 6 confirm that most heavy metals leached from the ore, are again precipitated on the surfaces of the minerals. The composition of the EDTA leachate indicates that it is mainly the distribution of the iron and copper that is affected by the different milling environments, with the copper contents in the pulp increasing by approximately 10 times for the stainless steel mill, and 15 times for the ceramic mill, compared to that of the steel mill. It is interesting that the flotation of sphalerite did not follow this sequence, but was highest for the stainless steel milled pulp. As expected the iron present on the ore milled in the steel environment was much higher, i.e. about 30-40 times than for the other environments. The iron contents of $1.86 \mathrm{~g} / \mathrm{L}$, or $4.1 \mathrm{~kg} / \mathrm{t}$, was higher than the normal milling media consumption in plant practice, but quite normal for laboratory batch grinding (Natarajan, 1992).

The amounts of lead and zinc leached did not differ significantly for the three milling environments, but was much higher for lead compared to zinc. Considering the low contents of lead in the ore, the values meant that about $12-16 \%$ of the lead in the ore was EDTA extractable. However, this high value was due to prior oxidation of the lead as identified using ammonium acetate leaching. High EDTA extractable lead was also reported by other researchers (Sui et al., 1995, Sui et al., 1999, Rumball and Richmond, 1996, Senior and Trahar, 1991 and Kant et al., 1994). The oxidation of the lead most 
probably occurred prior to milling and did not involve the transport of the lead to the sphalerite as its distribution was similar for the different milling environments. Although calcium, magnesium and barium are quite soluble at the flotation $\mathrm{pH}$ of $\approx 8.0$, the EDTA extractable concentration for calcium, magnesium and barium are much higher than their concentrations in solution (Table 6). The dissolution of dolomite in EDTA solution was reported to be faster than that in water (Fredd and Fogler, 1998). The over dosage of EDTA may be responsible for the difference. The molar ratio of EDTA extractable calcium to magnesium, $\mathrm{Ca} / \mathrm{Mg}$, is 2.9 rather than the stoichiometric unity. The reason for this difference may be caused by the nonstoichiometric dissolution of dolomite at the initial stage. The dissolution of calcite $\left(\mathrm{CaCO}_{3}\right)$ is much faster than that of magnesite $\left(\mathrm{MgCO}_{3}\right)$ (Brady and House, 1996). The ultimate dissolution is stoichiometric (Brady and House, 1996). The high sodium and potassium concentrations detected are at least partly due to the EDTA and $\mathrm{pH}$ regulator $(\mathrm{KOH})$ used for the leaching. The different milling methods resulted in considerable differences in both DO and Eh values for the pulps. Milling in a steel mill caused low Eh and DO values and an oxygen demand that could not be satisfied, even with aeration for more than $25 \mathrm{~min}$. The Eh values $(>200 \mathrm{mV})$ after aeration were all well above $137 \mathrm{mV}$, the calculated reversible potential of the dithiolate-thiolate reaction for SNPX (Seke, 2005); even the ore milled in steel achieved more positive potentials after a few minutes.

\section{Discussion}

Milling involves not only the physical process of size reduction, but also complicated surface chemical reaction processes. Different milling materials create different milling environments, hence different pulp chemistries. It is well known that milling in a steel mill will result in an anoxic condition, due to the consumption of the oxygen in the solution by the oxidizing of the iron required for the oxidation of iron to ferrous ions and also its further oxidation to ferric species. The primary dissolution process may also be further enhanced in ore environments, like for instance sulphides, that also enhance oxygen reduction through galvanic interactions (Wang and Xie, 1990, Natarajan, 1992 and Huang and Grano, 2006). For example, when grinding media is in contact with an electrically conducting sulphide like pyrites, the dissolution of the sulphide will not only 
be reduced but it will also act as an additional surface for the reduction of oxygen and so enhance the oxidation of the iron grinding media, as indicated below:

Oxidation of iron on grinding media:

$$
\mathrm{Fe} \rightarrow \mathrm{Fe}^{2+}+2 \mathrm{e}
$$

Cathodic reactions on pyrite surface:

$$
\mathrm{O}_{2}+2 \mathrm{H}_{2} \mathrm{O}+4 \mathrm{e} \rightarrow 4 \mathrm{OH}^{-}
$$

The overall reaction, being:

$$
2 \mathrm{Fe}+2 \mathrm{H}_{2} \mathrm{O}+\mathrm{O}_{2} \rightarrow 2 \mathrm{Fe}^{2+}+4 \mathrm{OH}^{-}
$$

Due to the alkaline $\mathrm{pH}$ of the system $(\mathrm{pH}=8.2)$ used, the dissolved iron will be precipitated as ferro-hydroxides, or after further oxidation as ferri-hydroxides or iron oxy-hydroxides. Heterogeneous precipitation of these iron precipitates on mineral surfaces should typically occur on the more cathodic mineral in a galvanic couple, such as may be formed between steel and pyrite in the milling environment. This is due to the fact that the iron species released from the steel, acting as an anode, will diffuse to the mineral, acting as the cathode, where the local $\mathrm{pH}$ will be higher due to the release of hydroxyl ions as a product of the oxygen reduction (Rao and Natarajan, 1990 and Sui et al., 1995). However, for neutral to alkaline conditions, this effect will be reduced because the iron will be precipitated in the solution before it reaches the mineral surface. The solubility of $\mathrm{Fe}(\mathrm{OH})_{2}$ at $\mathrm{pH} 8,8.5,9$ is about $5,0.5$, and $0.05 \mathrm{ppm}$ of $\mathrm{Fe}^{2+}$, respectively. However, the precipitation of $\mathrm{Fe}^{2+}$ in the milling and conditioning stages is difficult to predict as the compositions of the micro-environments may be significantly different from that of the bulk solution. In the case of significant dissolution of iron, unselective coating of minerals will probably occur. In the neutral $\mathrm{pH}$ range $\mathrm{FeOH}^{+}$may form and adsorb on negatively charged minerals. The sequence of zeta potentials of sphalerite, galena and pyrite in the neutral $\mathrm{pH}$ range will facilitate the adsorption of $\mathrm{FeOH}^{+}$on the more negatively charged galena and sphalerite, relative to the pyrite particles, and result in the selective depression of the former minerals. The coating of mineral surfaces with 
iron or lead oxides will be similar in nature to slime coatings, which typically reduce the floatability of minerals, such as galena (Gaudin et al., 1960 and Bandini et al., 2001). The relatively thick slime coating, compared to the collector layer, will significantly reduce interaction between mineral particle and air bubbles. The end result may be that precipitation of iron species occurs rather unselectively on most minerals and cause depression. But the sacrificial dissolution of the iron will also protect the more noble minerals from oxidation, and may so preserve their ability to interact with the collector and to be floated.

The oxidation of minerals during grinding may also cause inadvertent activation. The high copper contents in solution in the case of stainless steel milling, is probably caused by the oxidation of copper minerals at the high dissolved oxygen content in the environment, which is in contrast to the low oxygen contents resulting from milling in a steel environment, and this copper may cause the activation of sphalerite. The high copper content after milling in a ceramic environment is also expected, but not the lack of activation and low flotation recovery of sphalerite following milling in this environment, as indicated in Fig. 1 and Fig. 5. It should be noted that because copper is believed to be easily absorbed by sphalerite and pyrite, but may then transform to a state that is not EDTA extractable (Weisener and Gerson, 2000 and Rao, 2004), the copper leached with EDTA may only be a fraction of the copper present on the sphalerite.

It is generally agreed that there is a minimum degree of hydrophobicity for any specific particle required to be floated in a specific system (Trahar, 1981 and Blake and Ralston, 1985). The general relationship between floatability, hydrophobility and particle size is given by Trahar (1981). Coarse particles, and especially dense particles such as galena, may require a higher degree of hydrophobicity to be floated. For this reason coarse particles are more sensitive to the chemical environment when compared with intermediate or fine particles, and may even be used as an indicator of flotation conditions (Trahar, 1981). The surface precipitation of iron oxy-hydroxides on finer particles may not affect their flotation as severely as the better liberation of for instance sulphides, may counter the effect of coatings on the particles. However, for the coarse particles, which typically consist of intergrown minerals, the situation is quite different and coating with iron oxy-hydroxides may decrease or totally prevent the development of 
hydrophobicity. For the grinding in media that do not have reactive iron containing surfaces, this kind of coating is not significant, but the higher availability of dissolved oxygen may cause the dissolution of activating species, such as copper, silver and lead, from their minerals, and the activation of other sulphides, or even silicates. The increase in flotation of sphalerite with decreasing particle size after milling in steel, may be due to the low rate of oxidation of these in the anoxic conditions created in a steel comminution environment. The rather low flotation for sphalerite obtained after milling in the ceramic mill in the presence of significantly more dissolved copper is not understood.

The higher level of dissolved oxygen, and thus Eh, maintained during milling in the stainless steel and ceramic mills may have increased the collectorless floatability of sulphide minerals, especially galena, by the formation of hydrophobic sulphur oxidation products. It was reported that the collectorless flotation of sulphide minerals increase as the Eh increased (Trahar, 1984 and Ralston, 1994). This better floatability may increase the flotation selectivity, but would be difficult to distinguish from the activation caused by the increased copper levels in solution. Complexing of the copper by cyanide may be a means to prevent the activation by copper, but may also decrease the development of collectorless flotation by forming hydrophilic thiocyanides in stead of the hydrophobic sulphur species that forms in the absence of cyanide.

\section{Conclusions}

The following conclusions may be drawn from this work:

- The milling environments evaluated significantly affected the flotation of sulphide minerals. The usual steel mill environment tended to decrease the floatability of all the minerals, especially that of the coarse galena particles. However, the selectivity against sphalerite was better after milling in a steel mill, while milling in ceramic and stainless mill tended to increase the recovery of lead minerals, but decreased the flotation selectivity.

- The depression after comminution in the steel mill is probably caused by the unselective coating of minerals with iron oxy-hydroxides, originating from the oxidation of milling media. Coarse dense particles, such as that of lead containing minerals, are more susceptible to this kind of depression. 
- The activation of sphalerite, after comminution in the ceramic or stainless steel mills, was probably caused by increasing the mobility of copper species resulting from the more oxidizing environments present in these mills.

\section{References}

Ayyala et al., 1993 S. Ayyala, T.V. Subrahmanyam, R.J. Pugh and K.S.E. Forssberg, Effect of corrosion inhibitors on grinding and flotation of a lead-zinc ore, Minerals Engineering 6 (1993), pp. 929-935.

Bandini et al., 2001 P. Bandini, C.A. Prestidge and J. Ralston, Colloidal iron oxide slime coatings and galena particle flotation, Minerals Engineering 14 (2001), pp. 487-497. Blake and Ralston, 1985 P. Blake and J. Ralston, Particles size, surface coverage and flotation response, Colloids and Surfaces 16 (1985), pp. 41-53.

Brady and House, 1996 P.V. Brady and W.A. House, Surface-controlled dissolution and growth of minerals. In: P.V. Brady, Editor, Physics and Chemistry of Mineral Surfaces, CRC Press, LLC, USA (1996), pp. 225-305.

Forssberg et al., 1988 E. Forssberg, S. Sundberg and H. Zhai, Influence of different grinding methods on floatability, International Journal of Mineral Processing 22 (1988), pp. 183-192.

Forssberg et al., 1993 K.S.E. Forssberg, T.V. Subrahmanyam and L.K. Nilsson, Influence of grinding method on complex sulphide ore flotation: a pilot plant study, International Journal of Mineral Processing 38 (1993), pp. 157-175.

Fredd and Fogler, 1998 C.N. Fredd and H.S. Fogler, The influence of chelating agents on the kinetics of calcite dissolution, Journal of Colloid and Interface Science 204 (1998), pp. 187-197.

Gaudin et al., 1960 A.M. Gaudin, D.W. Fuerstenau and H.L. Miaw, Slime-coating in galena flotation, Canadian Mining and Metallurgical Bulletin 53 (1960), pp. 960-963. Greet and Smart, 2002 C.J. Greet and R.StC. Smart, Diagnostic leaching of galena and its oxidation products with EDTA, Minerals Engineering 15 (2002), pp. 515-522. 
Greet et al., 2004 C.J. Greet, G.L. Small, P. Steinier and S.R. Grano, The Magotteaux Mill $^{\circledR}$ : investigating the effect of grinding media on pulp chemistry and flotation performance, Minerals Engineering 17 (2004), pp. 891-896.

Greet et al., 2005 Greet, C.J., Kinal, J., Steinier, P., 2005. Grinding media-its effect on pulp chemistry and flotation behaviour - fact or fiction? In: Centenary of Flotation Symposium, AusIMM, Brisbane; pp. 967-972.

Huang and Grano, 2006 G. Huang and S. Grano, Galvanic interaction of grinding media with pyrite and its effect on floatation, International Journal of Mineral Processing $\mathbf{7 8}$ (2006), pp. 182-197.

Kant et al., 1994 C. Kant, S.R. Rao and J.A. Finch, Distribution of surface metal ions among the products of chalcopyrite flotation, Minerals Engineering 7 (1994), pp. $905-$ 916.

Kelsall, 1961 D.F. Kelsall, Application of probability in the assessment of flotation systems, Transactions of the Institution of Mining and Metallurgy 70 (1961), pp. 191204.

Kocabag and Smith, 1982 D. Kocabag and M.R. Smith, The effect of grinding media and galvanic interaction upon the flotation of sulphide minerals. In: A.D. Zunkel, R.S. Boorman, A.E. Morris and R.J. Wesley, Editors, Complex Sulphides, Processing of Ores, Concentrates and By-Products, The Metallurgical Society, Inc. (1982), pp. 55-81. Lynch et al., 1981 A.J. Lynch, N.W. Johnson, E.V. Manlapig and C.G. Thorne, Mineral and Coal Flotation Circuits: Their Simulation and Control, Elsevier, Amsterdam (1981) pp. 33-96.

Natarajan, 1992 K.A. Natarajan, Ball wear and its control in the grinding of a lead-zinc sulphide ore, International Journal of Mineral Processing 34 (1992), pp. 161-175. Natarajan, 1996 K.A. Natarajan, Laboratory studies on ball wear in the grinding of a chalcopyrite ore, International Journal of Mineral Processing 46 (1996), pp. 205-213. Pradip, 1992 Pradip, Scientific and technological challenges in mineral processing, Mineral Processing and Extractive Metallurgy Review 10 (1992), pp. 123-137.

Ralston, 1994 J. Ralston, The chemistry of galena flotation: principle and practice, Minerals Engineering 7 (1994), pp. 715-735. 
Rao, 2004 S.R. Rao (reviser) (2nd ed.), Surface Chemistry of Froth Flotation Vol. 1, Kluwer Academic/Plenum Publishers, New York (2004) pp. 190-191.

Rao and Natarajan, 1990 M.K.Y. Rao and K.A. Natarajan, Effect of electrochemical interactions among sulphide minerals and grinding medium on the flotation of sphalerite and galena, International Journal of Mineral Processing 29 (1990), pp. 175-194.

Rey and Formanek, 1960 Rey, M. Formanek, V., 1960. Some factors affecting selectivity in the differential flotation of lead-zinc ores in the presence of oxidized lead minerals. In: Proceedings of the 5th International Mineral Processing Congress, IMM, London; pp. $343-353$.

Rumball and Richmond, 1996 J.A. Rumball and G.D. Richmond, Measurement of oxidation in a base metal flotation circuit by selective leaching with EDTA, International Journal of Mineral Processing 48 (1996), pp. 1-20.

Seke, 2005 Seke, M.D., 2005. Optimisation of the selective flotation of galena and sphalerite at Rosh Pinah mine, PhD thesis: University of Pretoria, Pretoria, South Africa. Seke and Pistorius, 2005 M.D. Seke and P.C. Pistorius, The effect of mode of occurrence of galena and sphalerite on the selective flotation of ore samples from the Rosh Pinah mine, Journal of the South African Institute of Mining and Metallurgy 105 (2005), pp. 653-662.

Senior and Trahar, 1991 G.D. Senior and W.J. Trahar, The influence of metal hydroxides and collector on the flotation of chalcopyrite, International Journal of Mineral Processing 33 (1991), pp. 321-341.

Sui et al., 1995 C.C. Sui, S.H.R. Brienne, S.R. Rao, Z. Xu and J.A. Finch, Metal ion production and transfer between sulphide minerals, Minerals Engineering 8 (1995), pp. $1523-1539$.

Sui et al., 1999 C. Sui, J.C. Grimmelt, S.R. Rao and J.A. Finch, Lead ion production: test of pyrite:galena ratio and locked particle effects, Canadian Metallurgical Quarterly 38 (1999), pp. 211-213.

Trahar, 1981 W.J. Trahar, A rational interpretation of the role of particle size in flotation, International Journal of Mineral Processing 8 (1981), pp. 289-327. 
Trahar, 1984 W.J. Trahar, The influence of pulp potential in sulphide flotation. In: M.H. Jones and J.T. Woodcock, Editors, Principles of mineral flotation The Wark Symposium, Symposia Series, Australasian Institute of Mining and Metallurgy (1984), pp. 117-135. Vianna et al., 2003 Vianna, S.M., Franzidis, J.-P., Manlapig, E.V., Silvester, E., Fu, P.H., 2003. The influence of particle size and collector coverage on the floatability of galena particles in a natural ore. In: Proceedings XXII International Mineral Processing Congress, Cape Town, South Africa; pp. 816-826.

Wang and Xie, 1990 X.H. Wang and Y. Xie, The effect of grinding media and environment on the surface properties and flotation behaviour of sulphide minerals, Mineral Processing and Extractive Metallurgy Review 7 (1990), pp. 49-79.

Wei and Sandenbergh, 2005 Wei, Y., Sandenbergh, R., 2005. Evaluation of absorbents as a means to control the influence of heavy metal ions on the flotation of a complex sulphide ore. In: Centenary of Flotation Symposium, AusIMM, Brisbane; pp. 1057-1063. Weisener and Gerson, $2000 \mathrm{C}$. Weisener and A. Gerson, Investigation of the $\mathrm{Cu}$ (II) adsorption mechanism on pyrite by ARXPS and SIMS, Minerals Engineering 13 (2000) (13), pp. 1329-1340.

Young, 1974 R.S. Young, Chemical Phase Analysis, Charles Griffin \& Company Limited (1974) pp. 68-71.

Corresponding author. Tel.: +27 124203922. 